\title{
Identificación mediante Sistemas de Información Geográfica de áreas problemáticas de ganadería intensiva por incumplimiento de las normativas vigentes: el caso de la Comunidad Valenciana
}

\author{
C. Calafat-Marzal1,*, A. Gallego-Salguero² e I. Quintanilla-García² \\ 1 Departamento de Economía y Ciencias Sociales, Universitat Politècnica de Valencia, Camino de Vera s/n, \\ 46002, Valencia \\ 2 Departamento de Ingeniería Cartográfica, Geodesia y Fotogrametría de la Universitat Politècnica de \\ Valencia
}

\begin{abstract}
Resumen
Las reformas de las políticas europeas han evolucionado en busca de un modelo que permita a la agricultura y ganadería en las zonas rurales reconocer funciones como la conservación del medioambiente y el paisaje rural y la contribución de las zonas rurales al desarrollo de un territorio equilibrado. Sin embargo, para que el sector ganadero contribuya a estas funciones, debe corregir los riesgos sectoriales y ambientales que genera. Uno de los elementos clave para corregirlo es la planificación espacial de la ganadería. En áreas con mayor concentración ganadera el riesgo potencial es alto y la detección de riesgos es más compleja. El objetivo de este estudio es proponer y validar un procedimiento mediante Sistemas de Información Geográfica (SIG) que permita evaluar el riesgo de las explotaciones ganaderas teniendo en cuenta los criterios sectoriales, sociales y ambientales. Asimismo, se ha aplicado a la Comunidad Valenciana, una región con áreas de alta densidad de ganado con sistemas de producción intensiva, compuesta por 4984 granjas de las distintas especies ganaderas. Los resultados han identificado las áreas más problemáticas por incumplimiento de la legislación vigente. En la Comunidad Valenciana se han detectado principalmente dos áreas sensibles. En el área más problemática el $40 \%$ de las explotaciones están incumpliendo las normas vigentes, ninguna de las explotaciones respeta la distancia a otras explotaciones $y$, además, la mitad de estas no cumplen la distancia a los núcleos urbanos. En la otra área problemática el $33 \%$ de las explotaciones incumple las distancias mínimas a los núcleos urbanos y otras explotaciones. Estos resultados proporcionan información valiosa para diseñar y aplicar mejores políticas sectoriales, sociales y ambientales por parte de las administraciones públicas, responsables de la gestión de las actividades pecuarias y del territorio, a fin de reducir los riesgos para la población cercana a las explotaciones ganaderas.
\end{abstract}

Palabras clave: Política Agraria Común, riesgos medioambientales, riesgos para la salud pública, distancia entre granjas, densidad ganadera.

Geographic Information Systems detection of problematic areas of intensive livestock farming for non-compliance with the regulations in force: the case of the Valencian Community

Abstract

European policy reforms have evolved in search of a model that allows agriculture and livestock in rural areas to recognize functions such as the conservation of the environment and the rural landscape and the contribution of rural areas to the development of a balanced territory. However, for the lives-

* Autor para correspondencia: macamar3@esp.upv.es

Cita del artículo: Calafat-Marzal C, Gallego-Salguero A, Quintanilla-García I (2019). Identificación mediante Sistemas de Información Geográfica de áreas problemáticas de ganadería intensiva por incumplimiento de las normativas vigentes: el caso de la Comunidad Valenciana. ITEA-Información Técnica Económica Agraria 115(1): 31-51. https://doi.org/10.12706/itea.2018.025 
tock sector to contribute to these functions, it must correct the sectoral and environmental risks it generates. One of the key elements to correct it is the spatial planning of livestock. In areas with greater livestock concentration, the potential risk is high and the detection of risks is more complex.

The objective of this study is to propose and validate a procedure using Geographic Information Systems (GIS) to assess the risk of livestock farms taking into account sectoral, social and environmental criteria. Likewise, it has been applied to the Valencian Community, a region with areas of high density of livestock with intensive production systems, composed of 4984 farms of different livestock species. In the Valencian Community, two main sensitive areas were detected. In the most problematic area, $40 \%$ of farms are not in compliance with regulations, none of the farms respect the distance to other farms and half of the farms do not comply with the required distance to urban centres. In the other problematic area, $33 \%$ of farms violate the minimum distance to urban centres and distances to other farming operations. The results have identified the most problematic areas due to non-compliance with current legislation. These results provide valuable information for designing and applying better sectoral, social and environmental policies on the part of public administrations, responsible for the management of livestock and territory activities, in order to reduce the risks for the population close to the livestock farms.

Keywords: Common Agricultural Policy, environmental risks, risks to public health, distance between farms, Livestock density.

\section{Introducción}

La reestructuración del sector agrario, debida a la aplicación de las políticas agrarias y de cohesión territorial, ha producido cambios en la actividad agraria y cambios en los usos del suelo, en los paisajes y sociedades rurales (Brady et al., 2012; Tzanopoulos et al., 2012; Ruiz-Urrestarazu y Galdós-Urrutia, 2013; Pérez et al., 2016). Existe una correlación, de forma progresiva y explícita, entre las políticas y la transformación del territorio.

Las actuaciones a nivel europeo sobre el medio rural son el resultado de dos políticas principalmente: una agraria, la Política Agraria Común (PAC), y otra de cohesión territorial (económica y social). Los efectos territoriales de la PAC, aun siendo una política sectorial, son innegables $y$, por tanto, junto con las políticas de cohesión económica y social, señalan que la componente territorial es fundamental para la obtención de los resultados propuestos por estas iniciativas. Esta evidencia se expone en la Estrategia Territorial Europea (ETE), aprobada en 1999 en Alemania, donde se presenta la posibilidad de superar la pers- pectiva de las políticas sectoriales para observar la situación global del territorio europeo y tener en cuenta las oportunidades de desarrollo que presentan (Plaza, 2006). Esta perspectiva se plasma en las reformas de la PAC, que profundizan en aspectos territoriales (Herviu, 1996; Sumpsi, 1996; Segrelles, 2012;). La última reforma de la PAC (Hacia la PAC 2020) se basa, entre otras medidas, en la gestión sostenible de los recursos naturales y el desarrollo territorial equilibrado. En el caso de la ganadería estas reformas inciden directamente en la determinación de los riesgos que genera su actividad. Estos riesgos no dependen solamente del propio sector (problemas sectoriales por riesgo de seguridad sanitaria) sino que están muy influenciados por las características territoriales en las que se ubican las explotaciones ganaderas (Boender et al., 2014). Estos riesgos sectoriales son debidos, principalmente, a la transmisión de enfermedades entre explotaciones (seguridad sanitaria). Además generan riesgos sobre la salud pública, debido a que las explotaciones cercanas a núcleos de población generan molestias y riesgo de transmisión de enfermedades (Mahin, 2001; Van Boe- 
ckel et al., 2012; Schauberger et al., 2013; Lupindu et al., 2015; Richter et al., 2015), y sobre el medio ambiente, por la ubicación de explotaciones en usos del suelo no apropiados, como son usos protegidos (Centner, 2004; Perez, 2006; Deunert et al., 2007; Cejudo y Maroto, 2010; Palomo et al., 2013; Kros et al., 2015), o en zonas con elevado riesgo de aguas subterráneas (Bartelt-Hunt et al., 2011; Friedrich y Kassam, 2016).

En el estudio de la ordenación del territorio, en cualquier aspecto que se aborde, la componente geográfica es fundamental y los Sistemas de Información Geográfica (SIG) intervienen de forma destacada en multitud de estudios de investigación territorial con diversos objetivos, como son, resolver problemas de planificación y gestión del territorio (Baban y Parry, 2001; Salvà et al., 2004; Amador y Dominguez, 2005), proporcionar la capacidad de predecir y evaluar su impacto (Molina-Ruiz et al., 2011) y para una adecuada gestión del uso del suelo (Pettit, 2005).

La aplicación de los SIG para la realización de estudios relacionados con la agronomía ha tenido aplicaciones muy diversas, como por ejemplo en la predicción de modificaciones de la PAC en los servicios de uso de la tierra, la biodiversidad y los ecosistemas (Brady et al., 2012; Tzanopoulos et al., 2012). En el caso de la ganadería también se han utilizado ampliamente, algunos ejemplos son los estudios relacionados con la planificación de la ganadería (Calafat et al., 2015), con la identificación de zonas adecuadas para la aplicación de residuos animales (Basnet et al.,2002) o los estudios referidos a los residuos ganaderos y su utilización en la generación de energías renovables, donde existen aplicaciones para estimar la producción de biogás a partir del estiércol de todas las principales especies ganaderas (Batzias et al.,2005).

El objetivo de estudio es analizar espacialmente el sector ganadero de la Comunidad Valenciana (CV), deteniéndose en las explota- ciones intensivas por ser más generadoras de riesgos sobre el propio sector, el medio ambiente y los núcleos de población, e identificar, mediante técnicas SIG, aquellas explotaciones que no cumplen con los criterios definidos en las distintas legislaciones que afectan al sector. Se parte de la hipótesis que todas las explotaciones ganaderas de la CV no se cumplen actualmente las normativas para reducir los riesgos que genera su actividad. Sigue habiendo instalaciones ganaderas ubicadas en áreas en las que actualmente está restringida la actividad, generando riesgos tanto para el propio sector, como para la salud pública y el medioambiente.

La aportación novedosa de este artículo se centra en la localización geográfica de las explotaciones ganaderas e identificación de los riesgos asociados a las explotaciones mediante técnicas SIG. Para ello, se considera no sólo las distancias entre explotaciones y a los núcleos de población, sino también la ubicación de las explotaciones según las distintas clasificaciones del suelo, debido a que algunas explotaciones ganaderas pueden estar localizadas en calificaciones de usos del suelo no apropiadas.

La unificación de criterios nos permite evaluar el grado de la problemática territorial ganadera al delimitar áreas con mayor concentración de explotaciones ganaderas problemáticas y, por tanto, considerarlas como áreas de actuación prioritarias.

El artículo se estructura de la siguiente forma: en el apartado "materiales y métodos", en primer lugar, se describen el área de estudio y las características de las explotaciones ganaderas, seguidamente se explica la implementación de las normativas vigentes mediante técnicas de los SIG. A continuación se exponen los resultados obtenidos y la discusión planteada en la investigación, en los apartados correspondientes. Por último, el último apartado resume las principales conclusiones del estudio. 


\section{Material y métodos}

\section{Área de estudio y características de sus explotaciones ganaderas}

El área de estudio es una región situada al este de España, perteneciente a la zona mediterránea de Europa Occidental: la Comunidad Valenciana (Figura 1). Tiene una superficie de $23.250 \mathrm{~km}^{2}$ y cuenta con una población de más de 4 millones de habitantes. Aproximadamente el $44 \%$ de su superficie terrestre se utiliza para fines agrícolas, mientras que aproximadamente el $52 \%$ de la CV es superficie forestal.

El sector ganadero es principalmente intensivo y concentrado. Intensivo al concentrar en una área pequeña un elevado número de animales. Concentrado en referencia a que las especies ganaderas se agrupan en áreas cercanas (Calafat et al., 2015). En el estudio se analiza toda la superficie de esta región y considera el total de las explotaciones ganaderas de producción intensiva de más de una Unidad Ganadera Mayor (UGM) de las principales especies ganaderas (4984 explotaciones), como son del sector porcino y aves de engorde, conejos, caballos, bovino, ovino y caprino (Tabla 1). Se han eliminado las explotaciones de autoconsumo, es decir, las de menos de 1 UGM (es el equivalente en tamaño a un bovino adulto, y a un tercio en el resto de especies cuando no se supere dicha capacidad). En la Figura 1 se incluyen distribución de las explotaciones ganaderas a lo largo del territorio de la CV y la concentración de las explotaciones en el territorio (UGM/km²).

La topografía de esta zona delimita entornos regionales que difieren sustancialmente, estableciéndose tres áreas orográficas: zona interior, intermedia y costera. En cada una de ellas las políticas agrarias y sectoriales han repercutido de modo distinto. La zona interior se caracteriza por pastizales, bosques, matorrales, maleza, la producción extensiva de madera, abandono de tierras y terrazas. La
Tabla 1. Número de granjas por especies en la Comunidad Valenciana.

Table 1. Number of livestock farms in Valencian Community.

\begin{tabular}{lcr}
\hline Especie ganadera & Numero de granjas & \multicolumn{1}{c}{$\%$} \\
\hline Bovino & 688 & 13,80 \\
Caballos & 173 & 3,47 \\
Porcino & 1229 & 24,66 \\
Aves & 787 & 15,79 \\
Conejos & 301 & 6,04 \\
Ovino y caprino & 1806 & 36,24 \\
\hline Total & 4984 & 100,00 \\
\hline
\end{tabular}

zona intermedia incluye las ciudades, la producción intensiva de madera, usos de la tierra seca, la urbanización y los cultivos de riego. En la zona litoral caracterizada como regiones industrializadas, se producen más conflictos por el uso del suelo y, el efecto de las actividades turísticas y el fenómeno residencial han reducido el sector agrario (Recatalá et al, 2000).

En Las zonas más interiores (caracterizadas como regiones rurales principalmente, a excepción de zonas turístico-recreativas como las estaciones de esquí) las políticas se han diseñado para dinamizar las sociedades rurales, preservando los valores y potencialidades de estas áreas, frenando el deterioro de sus paisajes y corrigiendo los efectos negativos que sobre estas áreas han generado prácticas poco respetuosas con el medioambiente.

Las normativas aplicables a las explotaciones ganaderas provienen de cuatro ámbitos distintos: La Unión Europea, el Estado Español, la Comunidad Valenciana y los municipios. En el ámbito europeo, las regulaciones normativas establecen las obligaciones que deben cumplir las actividades industriales y agrícolas con un elevado potencial de contaminación, a través 


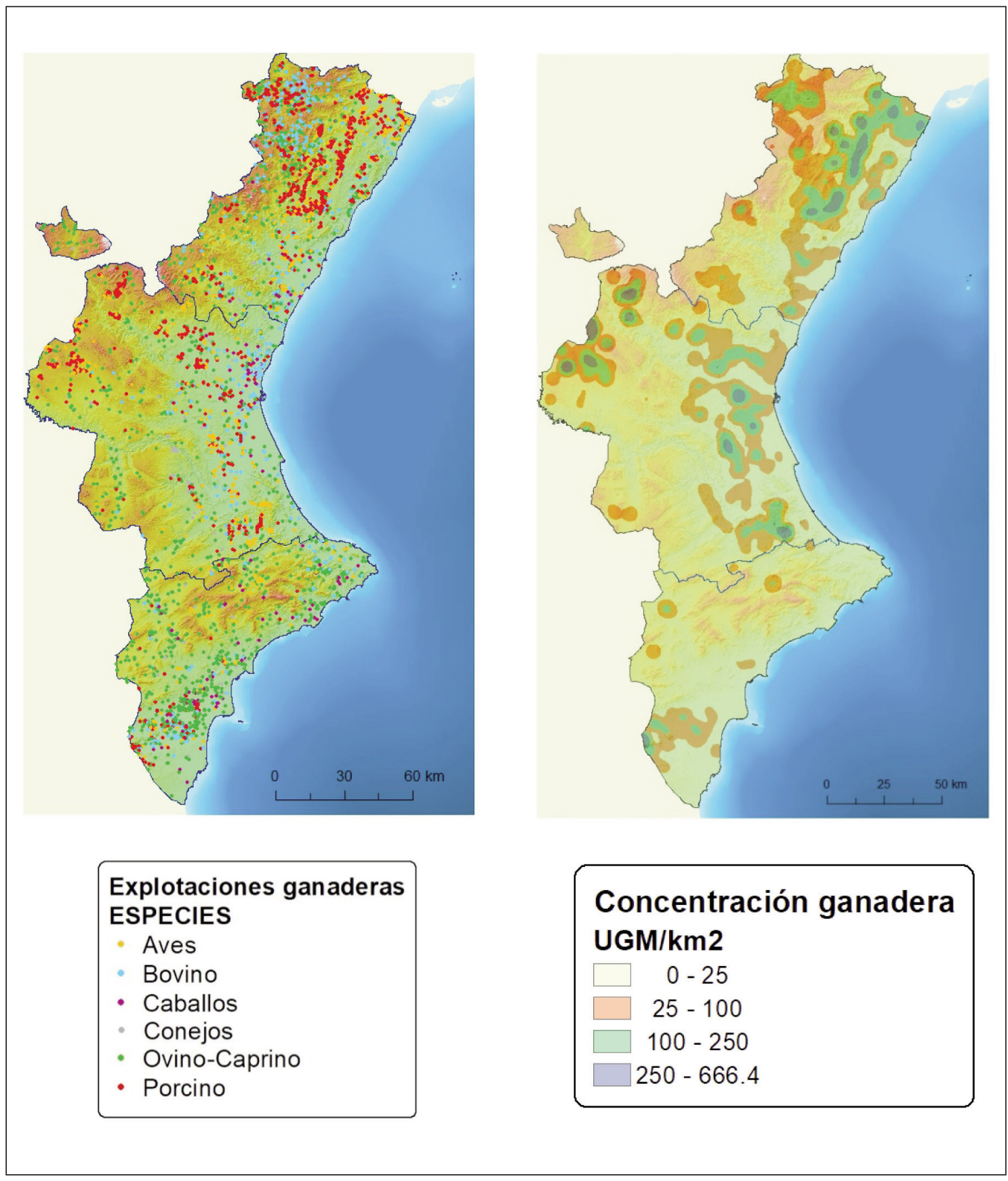

Figura 1. Mapa de explotaciones ganaderas por especies y mapa de la concentración ganadera en la Comunidad Valenciana.

Figure 1. Map of livestock farms by species and map of the livestock concentration in the Valencian Community. 
de la Directiva 2010/75/UE sobre emisiones industriales, orientada a la necesidad de obtener mejoras ambientales y en la salud pública, asegurando la rentabilidad y fomentando la innovación técnica, y de la Directiva relativa a la contaminación por nitratos (Directiva 91/676/CEE). Estas Directivas tienen su trasposición a niveles nacionales (En España: Ley 5/2013; Real Decreto 261/96) y regionales (en la Comunidad Valenciana: Ley 6/2014, Decreto 13/2000 y 11/2004). Además, algunos estados miembros han elaborado normativas de ordenación de las explotaciones porcinas, por ser la especie más contaminante, como es el caso de España.

Siguiendo estas normativas se estudiará la situación de la ganadería en la CV teniendo en cuenta el emplazamiento de cada una de las explotaciones.

\section{Criterios restrictivos utilizados}

En la Ley de Ganadería de la CV (Ley 6/2003, de 4 de marzo, de la Generalitat, de Ganadería de la Comunidad Valenciana) se establecen como criterios de ordenación las distancias entre las explotaciones ganaderas y a los núcleos urbanos. Además, se especifica la calificación urbanística del suelo en la que deben situarse las explotaciones ganaderas, determinando como única ocupación adecuada el suelo no urbanizable común. Estas normativas han sido de inmediato cumplimiento para las nuevas instalaciones, mientras que a las que ya estaban operativas, se les ha permitido el mantenimiento temporal de la actividad durante quince años desde la aprobación de la Ley. Por tanto, esta Ley de la Ganadería establece los criterios para corregir los riesgos de seguridad sanitaria y sobre la salud pública. Pero se desconoce el estado actual de los riesgos potenciales de las explotaciones ganaderas, dado que no se ha realizado un diagnóstico de la situación actual.

Además, las explotaciones ganaderas pueden generar riesgos de contaminación de aguas subterráneas, y por ello, se estudiará la ubicación de cada explotación ganadera y su grado de vulnerabilidad a los acuíferos de la zona.

\section{Datos de inicio y fuentes cartográficas iniciales}

En la Figura 2 se describe el flujo de trabajo para analizar los riesgos de seguridad sanitaria, de salud pública y sobre el medio ambiente de cada una de las explotaciones ganaderas, acorde a la legislación vigente. Para ello se utilizan como datos iniciales (inputs) la ubicación de las explotaciones ganaderas y las fuentes cartográficas iniciales de datos descritas en la tabla 2.

Las explotaciones se georreferenciaron con un receptor GNSS (Global Navigation Satellite System) de posicionamiento absoluto, que realizaba observaciones sobre el sistema GNSS de EEUU, denominado GPS (Global Position System). El proceso de definición de la posición geográfica de un elemento, o georreferenciación, consiste en atribuir valores de latitud y longitud a dicho elemento. Para el estudio de la ganadería, las coordenadas registradas con el GPS se corresponden con la ubicación de la granja. Estos protocolos permiten georreferenciar elementos dentro de un sistema de referencia geodésico unificado y estandarizado (Joost et al., 2010). Tantos las explotaciones, como todas las capas de datos geográficos utilizadas, se proyectaron en el sistema Universal Transversa de Mercator (UTM), en el huso 30, tomando como datum geodésico espacial el Sistema de Referencia Terrestre Europeo de 1989 (ETRS89), que, a efectos de precisión para este análisis, es compatible con el sistema de referencia oficial del GPS, el WGS-84 (World Geodetic System 1984).

A partir de las fuentes cartográficas de la Tabla 2 se han implementado las normativas vigentes, determinando en cada uno de los riesgos los criterios restrictivos (Figura 3): 


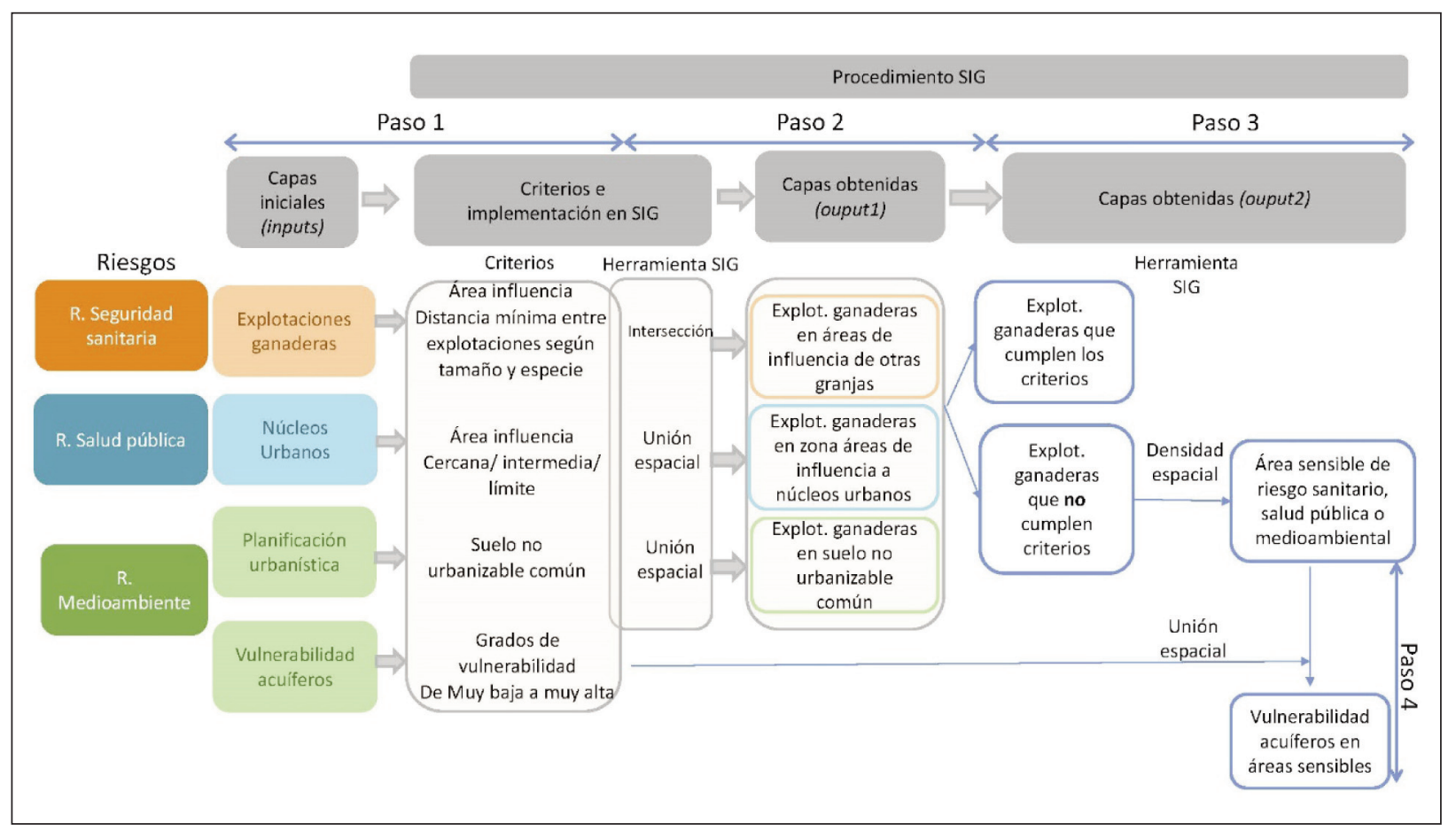

Figura 2. Flujo de trabajo para la implementación de los criterios restrictivos en SIG.

Figure 2. Workflow for the implementation of the restrictive criteria in GIS.

Tabla 2. Datos y fuentes cartográficas utilizadas.

Table 2. Data and cartographic sources used.

\begin{tabular}{llcl}
\hline Datos & Proveedor/Formato/Escala & Fecha de publicación & Web \\
\hline $\begin{array}{l}\text { Núcleos urbanos } \\
\text { Edificaciones aisladas } \\
\text { Límites Administrativos }\end{array}$ & $\begin{array}{l}\text { Institut Cartogràfic Valencià / } \\
\text { Vectorial en formato Shapefile / 1:5.000 }\end{array}$ & 2014 & \\
Planeamiento urbanístico & $\begin{array}{l}\text { Servicio de Coordinación Urbanística y } \\
\text { Territorial de la Conselleria d'Habitatge, } \\
\text { Obres Públiques i Vertebració del Territori / } \\
\text { Vectorial en formato Shapefile / 1/25.000 }\end{array}$ & 2008 & www.icv.gva.es \\
Mapa de vulnerabilidad \\
$\begin{array}{l}\text { Antigua Conselleria d'Obres Públiques, } \\
\text { de acuíferos }\end{array}$ & $\begin{array}{l}\text { Urbanisme i Transport (COPUT) - Generalitat } \\
\text { Valenciana / Vectorial en formato } \\
\text { Shapefile / 1:50.000 }\end{array}$ & \\
\hline
\end{tabular}


- Riesgos sectoriales (o de seguridad sanitaria entre explotaciones): se establecen las distancias mínimas entre instalaciones ganaderas, distinguiendo entre explotaciones de la misma o distinta especie ganaderas y el tamaño de las explotaciones.

- Riesgos sobre la salud pública: se establecen las distancias mínimas a núcleos de población dependiendo del número de habitantes.

- Riesgos medioambientales: se analizará el riesgo para las aguas subterráneas (vulnerabilidad de contaminación de acuíferos) y para la biodiversidad (considerando la ubicación de las explotaciones en calificaciones urbanísticas del suelo no apropiadas, como son las zonas cercanas a áreas urbanas, urbanizables y rurales protegidas o de dominio público).

Los criterios utilizados se describen a continuación, teniendo en cuenta los estudios que lo demuestran y la legislación vigente que los considera:

\section{Distancias de seguridad sanitaria entre explotaciones ganaderas de la misma especie}

En el análisis realizado por Boender et al. (2014) se demuestra como el tamaño de las explotaciones y la distancia entre explotaciones de porcino influyen en el riesgo de transmisión del virus de la peste porcina clásica entre granjas. Determinando que cuanto mayor sea el tamaño de la explotación y menor sea la distancia mayor será el riesgo de transmisión.

La Ley de Ganadería de la CV, en prevención de transmisión de enfermedades, indica que las granjas ganaderas guardarán una distancia mínima de 1000 metros con respecto a otras instalaciones de la misma especie ganadera. Esta distancia se reducirá a la mitad en el caso de explotaciones porcinas, avícolas y cunícolas con una capacidad inferior a 120 UGM, y a la tercera parte en el resto de las especies cuando no se alcance dicho tamaño.

Distancias de seguridad sanitaria entre explotaciones ganaderas de diferente especie

Según la Ley de Ganadería de la CV, en el caso de instalaciones ganaderas de distinta especie, con carácter general, la distancia entre ellas será como mínimo de $1000 \mathrm{~m}$.

Distancias de las explotaciones a los núcleos de población

Uno de los motivos de la expansión de la ganadería urbana y peri-urbana es el aumento creciente de las urbanizaciones y de la demanda de alimentos de origen animal. Esta práctica supone un riesgo para la salud pública al considerar que el ganado genera reservorios de patógenos zoonóticos (Lupindu et al., 2015).

En este sentido, la Ley de Ganadería de la CV regula la distancia mínima que debe existir entre las instalaciones ganaderas y los núcleos de población, estableciendo una distancia de 1000 metros con respecto a los núcleos de población de más de 2000 habitantes, de 500 metros como mínimo para núcleos entre 500 y 1999 habitantes, y de 250 metros para núcleos de población inferiores a 500 habitantes.

A partir de esta información se generaron buffers o áreas de influencia alrededor de cada núcleo, delimitando las zonas donde no deben ubicarse instalaciones ganaderas. Dentro de esta área de influencia, se definieron dos zonas más, una zona próxima al núcleo de población y una zona intermedia.

Las distancias, en metros, utilizadas para generar las tres zonas descritas anteriormente se presentan en la Figura 3. 


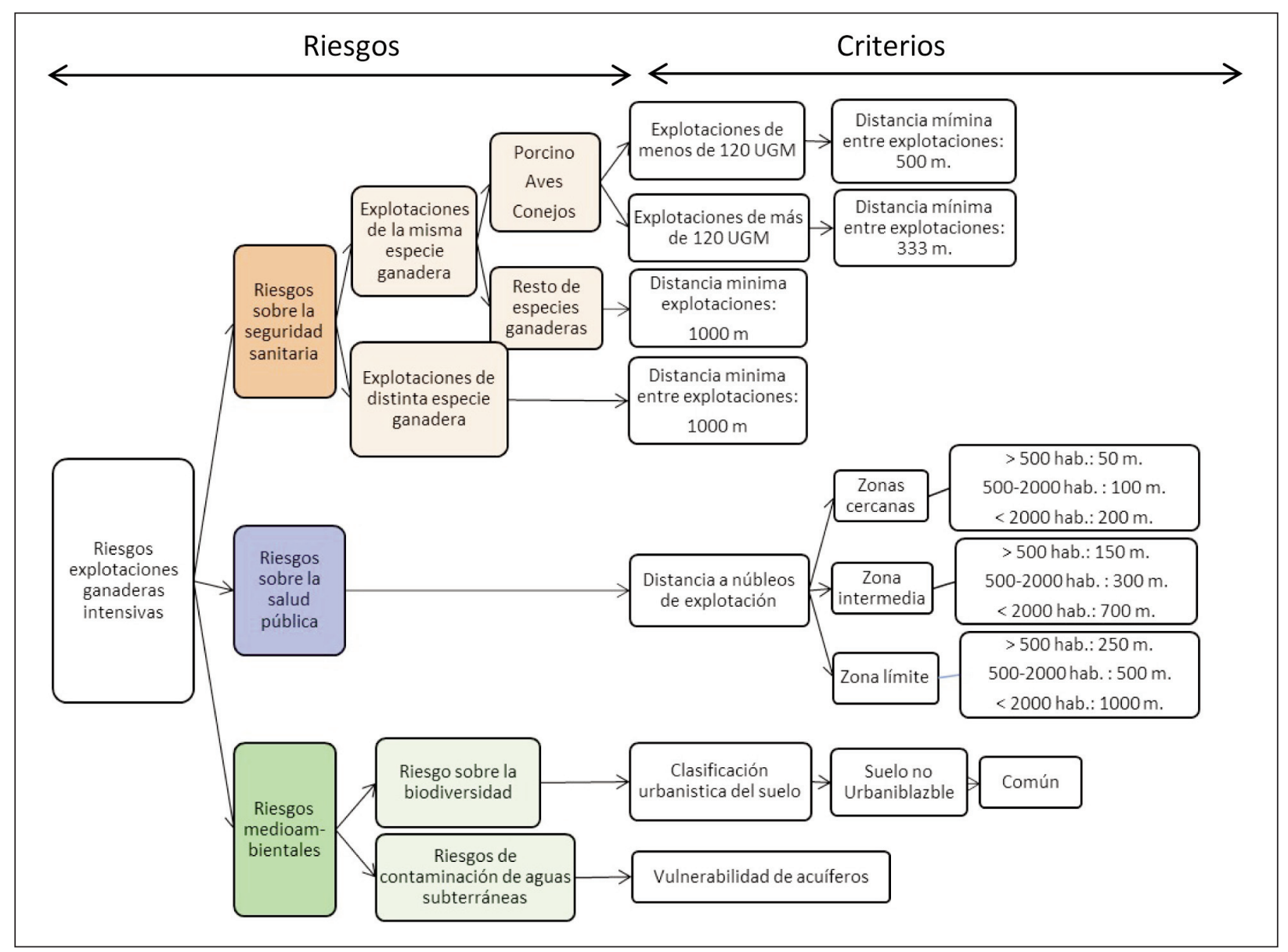

Figura 3. Riesgos de las explotaciones ganaderas de acuerdo a su localización geográfica y criterios utilizados. Figure 3. Livestock farms risks according to geographical location and criteria used.

\section{Clasificación urbanística del suelo}

La designación de áreas protegidas es uno de los indicadores disponibles más importantes para la conservación a largo plazo de la biodiversidad (Palomo et al., 2013). Para ello las áreas protegidas deben estar a salvo de posibles perturbaciones futuras (de Vos et al., 2016). Estas zonas se hallan amenazadas por los efectos negativos de la producción ganadera, siendo necesario establecer directrices sobre los usos del suelo adecuados para el establecimiento de las actividades ganaderas.
La Ley de Ganadería de la CV especifica, en relación a la clasificación del suelo, que las explotaciones ganaderas deberán situarse en terrenos con suelo no urbanizable.

El planeamiento urbanístico (Clasificación) de la CV está confeccionado a partir del planeamiento aprobado en las Comisiones Territoriales siguiendo el Decreto 74/2016, de 10 de junio, del Consell. Siguiendo esta clasificación el suelo no urbanizable (SNU) se puede clasificar en cuatro categorías: común (SNU común), protegido (SNU protegido), de 
dominio público (SNU dominio público) y con otras protecciones (SNU otras protecciones). Siendo el único conveniente el SNU calificado como común. De esta forma se ha analizado las explotaciones situadas en zonas no aptas para la actividad ganadera.

\section{Vulnerabilidad de las aguas subterráneas}

La agricultura y la ganadería están consideradas como una de las principales actividades responsables de la contaminación difusa de las aguas subterráneas, y por tanto de las altas concentraciones de nitratos que contienen (Nolan et al., 1997; Jarvis y Ledgard, 2002;), ya que existe una relación entre la alta densidad ganadera de una zona y los niveles de eutrofización de las aguas subterráneas (Djodjic et al., 2002). Este riesgo de contaminación de la ganadería está, especialmente, asociado a ganadería intensiva (Bartelt-Hunt et al., 2011; Friedrich y Kassam, 2016).

En esta línea, la Generalitat Valenciana, en el marco de un convenio suscrito en el año 1998 entre la antigua Consellería de Obras Públicas, Urbanismo y Transporte y la Universidad Politécnica de Valencia, realizó la Cartografía sobre la vulnerabilidad de las aguas subterráneas por actividades urbanísticas en la CV, a escala 1:50.000. En ella se contempla la división del territorio en zonas homogéneas caracterizadas por el grado de protección que ofrece el medio a la transmisión y difusión de los agentes contaminantes hacia las aguas subterráneas, estableciendo una base en los procesos de toma de decisiones que afectan a los usos del territorio las variables relacionadas con la calidad y la disponibilidad de los recursos hídricos, lo que permite conocer las aptitudes y limitaciones del territorio para el uso ganadero.

El grado de vulnerabilidad a la contaminación se define por combinación de las clases de sensibilidad de las variables significativas propuestas (permeabilidad, espesor no satu- rado y calidad de las aguas). En la tabla 3 se describe la adecuación de cada categoría de vulnerabilidad de los acuíferos a las distintas calificaciones urbanísticas del suelo.

Estableciendo las categorías de "Vulnerabilidad muy baja", que engloba zonas prácticamente invulnerables para las aguas subterráneas, principalmente por inexistencia de acuíferos, hasta la categoría "Vulnerabilidad muy alta" donde se incluyen las zonas del territorio especialmente sensibles para las aguas subterráneas.

\section{Implementación de los criterios restrictivos con los SIG}

A partir de las capas de datos iniciales del apartado anterior se han implementado los criterios restrictivos debido a los riesgos de las explotaciones ganaderas. Esta implementación de los criterios se detalla paso a paso en la Figura 2.

\section{Paso 1}

Partiendo de las capas de datos iniciales de las explotaciones ganaderas y las áreas urbanas se generaron áreas de influencia alrededor de cada explotación ganadera y de los núcleos de población, según las distancias establecidas en la Figura 3. Para los núcleos urbanos se delimitaron las zonas donde no deben ubicarse instalaciones ganaderas, definiéndose las zonas de influencia descritas (cercana, intermedia y límite).

La capa de las explotaciones se asoció a los datos de la distancia a las áreas urbanas, entre explotaciones y la planificación urbanística.

\section{Paso 2}

La determinación de las explotaciones que se encuentran dentro del área de influencia sanitaria de otra explotación se realizó con una intersección de capas. Con esta operación de análisis espacial se obtienen las ex- 
Tabla 3. Usos urbanísticos para cada categoría de vulnerabilidad de los acuíferos.

Table 3. Urban uses for each aquifers vulnerability category.

\begin{tabular}{ll}
\hline Categoría de vulnerabilidad & Adecuación de uso urbanístico \\
\hline I. Muy baja & Todos los usos compatibles \\
II. Baja & $\begin{array}{l}\text { Compatible con los usos residenciales intensivos y extensivos, } \\
\text { presentando limitaciones para los usos industriales intensivos } \\
\text { por el riesgo de contaminación físico-química de elevada carga } \\
\text { que comportan, aunque pueden ser compatibles usos industriales } \\
\text { aislados o industria urbana. }\end{array}$
\end{tabular}

III. Media

Compatible con los usos residenciales intensivos y extensivos desde el punto de vista de contaminación de las aguas subterráneas, presentando limitaciones para los usos industriales intensivos por el riesgo de contaminación físico-química de elevada carga que comportan, aunque pueden ser compatibles usos industriales aislados o industria urbana.

IV. Alta

Son desaconsejables los usos urbanísticos industriales y residenciales intensivos, así como la protección por interés agrícola intensivo, que facilita las labores de transformación agrícola, generadoras de contaminación extensiva por nitratos lixiviados de los procesos de abonado. Los usos residenciales extensivos pueden ser tolerados siempre que el saneamiento y la depuración efectiva de las aguas queden garantizados.

V. Muy alta

Solo compatibles para las zonas de descarga o emergencia de aguas subterráneas, tanto manantiales como zonas húmedas, incluso aquellas en las que la contribución hídrica de la componente subterránea es mínima, pero que tienen valor medioambiental.

Fuente: Elaboración propia a partir de la cartografía temática de la Generalitat Valenciana.

plotaciones que están dentro del área de influencia de otras explotaciones y, por tanto, se distinguen las explotaciones que cumplen de las que no cumplen las distancias mínimas reglamentarias.

La asignación de la distancia a la que se encuentran las explotaciones con respecto a los núcleos urbanos se realizó con una unión espacial de datos entre la capa de las explotaciones ganaderas y la que contiene las áreas de influencia de los núcleos urbanos.

El último factor considerado determina las instalaciones ganaderas que no están ubicadas en el suelo clasificado como SNU común.
Para ello, se han localizado los usos compatibles con dicha clasificación a partir de la capa disponible de la planificación urbanística de la CV. Para determinar la calificación del suelo en la ubicación de las explotaciones se realizó una unión entre la capa de las explotaciones y la capa que contiene la calificación del suelo.

\section{Paso 3}

A partir de la información extraída para cada uno de los factores, se obtuvo un valor final (índice de riesgo) para cada explotación en función del número de factores que no cum- 
plen. De manera que una explotación ganadera con riesgo nulo indica que está a una distancia suficiente para no generar riesgo sanitario a otra explotación, ya sea de la misma o distinta especie, además, también está a una distancia suficiente de los núcleos de población y es en una zona de SNU común. En cambio, una explotación con un índice de riesgo muy alto indica que está a una distancia insuficiente de otra explotación, tanto de la misma como de distinta especie, y por tanto genera riesgos sanitarios, además está a una distancia insuficiente de los núcleos de población y no es una zona de SNU común.

Es decir, el riesgo puede tener valor nulo si la explotación cumple todos los criterios, y valor uno (muy bajo), dos (bajo), tres (alto) o cuatro (muy alto) según el número de criterios que incumple.

A partir del índice de riesgo de cada explotación se identificaron las zonas con mayor concentración de explotaciones con riesgo muy alto, y por tanto de explotaciones que incumplen la legislación vigente (Áreas problemáticas o sensibles). Este mapa se representó mediante un mapa de densidad. Con el cálculo de la densidad se obtiene, mediante interpolación a partir de los puntos muestrales, los valores normalizados por unidad de superficie en toda el área de estudio. En este mapa se ponderó el índice anterior según si la explotación se encontraba en la zona cercana, intermedia o limite, dando mayor peso al área cercana.

\section{Paso 4}

Una vez identificadas las zonas más sensibles debido al incumplimiento de la legislación vigente, se evaluó la vulnerabilidad de dichas zonas con respecto a las aguas subterráneas. Este riesgo no está explícitamente regulado en la legislación, pero los estudios sobre contaminación de aguas subterráneas indican que la ganadería es uno de los principales focos de contaminación. Para ello se realizó una unión espacial de la capa de las áreas sensibles con la capa de vulnerabilidad de acuíferos.

\section{Resultados}

Los resultados obtenidos mediante la utilización de las técnicas SIG se clasifican en dos grupos: los mapas con la implementación directa de los criterios (output1) y los resultados a partir de estos (output2).

En los resultados iniciales (output1) se distinguen las explotaciones que cumplen de aqueIlas que no cumplen cada uno de los criterios. Así, en el riesgo por seguridad sanitaria se han establecido las áreas de influencia de cada explotación según este criterio y se han obtenido las explotaciones que están a una distancia menor de la indicada por la Ley para las explotaciones de la misma o distinta especie ganadera. Este procedimiento se ha repetido para cada una de las especies ganaderas. En la Figura 4 se muestra un ejemplo para el caso de las explotaciones avícolas. En la Figura 4a se presenta el mapa con las áreas de influencia de cada una de las explotaciones y en la Figura $4 \mathrm{~b}$ se distingue entre las explotaciones que cumplen los criterios de las que no lo cumplen. En el detalle de esta figura se aprecian las explotaciones en color verde porque respetan las distancias de estos criterios de riesgo de seguridad sanitaria y en rojo las explotaciones que no siguen estos criterios normativos.

Los resultados del riesgo de salud pública se representan en la Figura 5. En el mapa de la Figura 5a se presenta el área de influencia cercana, intermedia y límite a los núcleos urbanos. En el mapa de la figura $5 b$ se distinguen las explotaciones que no están dentro de estas áreas de influencia, y por tanto no presentan este riesgo, de las que sí están ubicadas en estas áreas. 


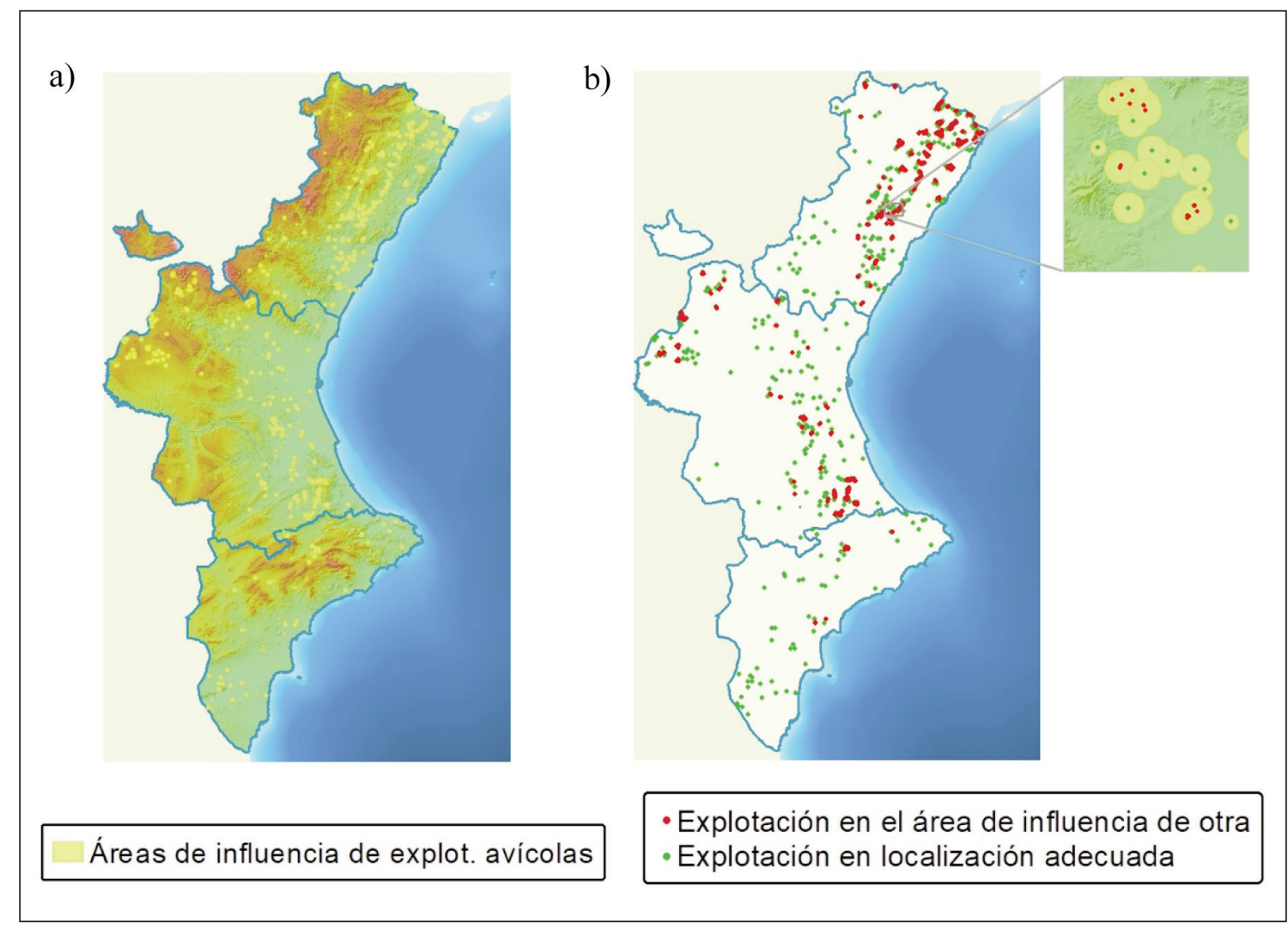

Figura 4. Mapa de las áreas de influencia de cada explotación (a) y mapa de identificación de las explotaciones según los criterios de seguridad sanitaria (b). Ejemplo de las explotaciones avícolas.

Figure 4. Map of the areas of influence for each farm (a) and farm identification map according to sanitary safety criteria (b). Example of poultry farms.

El riesgo medioambiental por incumplimiento del planeamiento se representa en la Figura 6. La Figura 6a corresponde con el mapa de la CV según las distintas planificaciones urbanísticas. Se puede observar que en la zona costera se concentra la mayor parte de los núcleos urbanos y, además, los de mayor población (regiones industriales). En cambio, la distribución ganadera concentra las zonas con mayor densidad en la zona intermedia e interior (regiones rurales). Siendo estas últimas donde existe mayor cantidad de suelo calificado como SNU común. Por tanto, si analizamos la relación entre la distribución de la ganadería y los núcleos urbanos, encontramos que las principales zonas ganaderas se sitúan en áreas en las que existe una baja densidad de habitantes y más SNU común. En el mapa de la Figura $6 \mathrm{~b}$ se distinguen las explotaciones que están en SNU común de las que no los están.

Los resultados obtenidos a partir de la clasificación de las explotaciones según los criterios (Output2) se presentan en las figuras siguientes. En la Figura 7a se representa el mapa según el índice de riesgo de cada explotación ganadera, es decir, el índice de inadecuación de la ubicación de las explotaciones. 


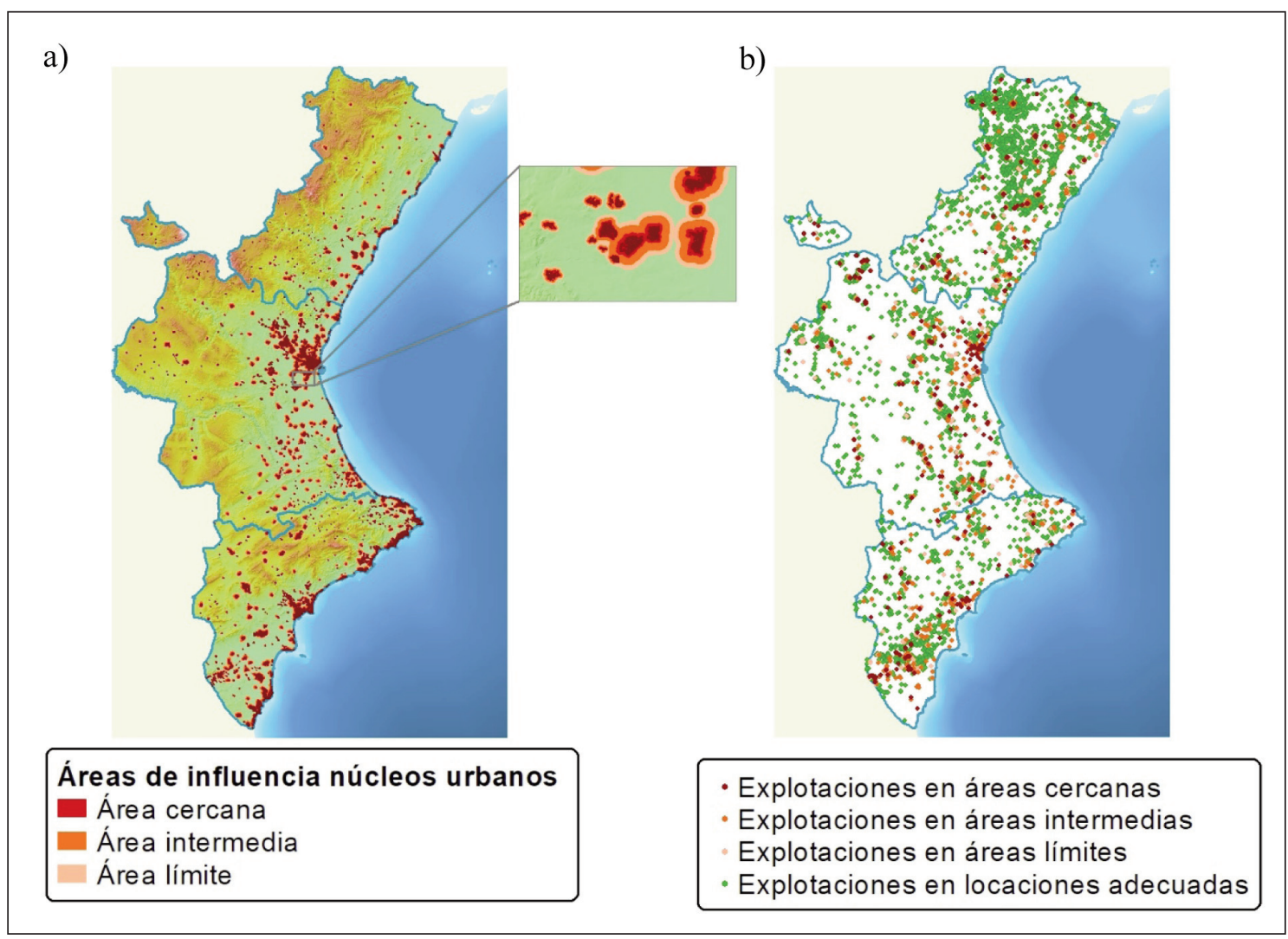

Figura 5. Mapa de las áreas de influencia de los núcleos urbanos (a) y mapa de las explotaciones que cumplen el criterio de salud pública (b).

Figure 5. Map of the urban centers influence areas (a) and map of farms that fulfill the criteria of public health (b).

En la figura 7b se identifican las áreas con mayor concentración de explotaciones con mayores riesgos, destacando la zona del norte de la CV (áreas con color azul), como áreas sensibles o problemáticas para la ganadería.

Los datos obtenidos indican que el $10,67 \%$ de las explotaciones tiene riesgo nulo y menos del $4 \%$ riesgo muy alto. El $32,42 \%$ incumplen uno de los criterios y el $53 \%$ restante más de uno. El criterio que más explotaciones incumplen es el de la distancia a explotaciones de distinta especie.
En estas áreas sensibles se ha analizado el riesgo medioambiental de contaminación de aguas subterráneas. En la figura $8 a$ se incorpora el mapa de vulnerabilidad de los acuíferos de la CV. En la Figura 8b se muestran las áreas sensibles según el grado de vulnerabilidad de los acuíferos. Se identifican dos zonas en las que, siendo áreas muy sensibles (riesgo muy alto), la vulnerabilidad de los acuíferos es baja.

De esta forma se valida la metodología utilizada, ya que se han determinado dos zonas 
a)
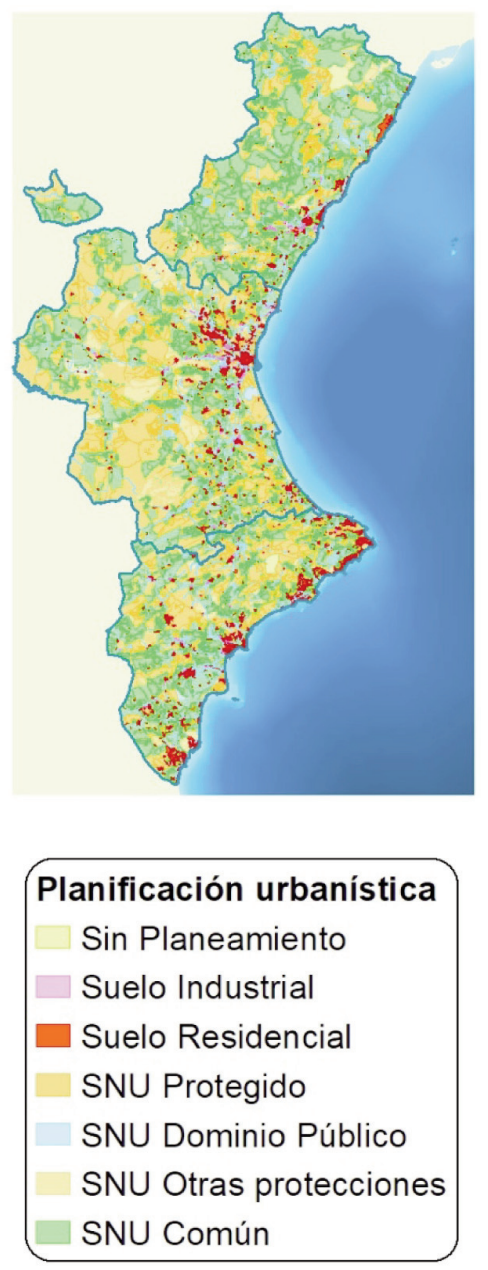

b)

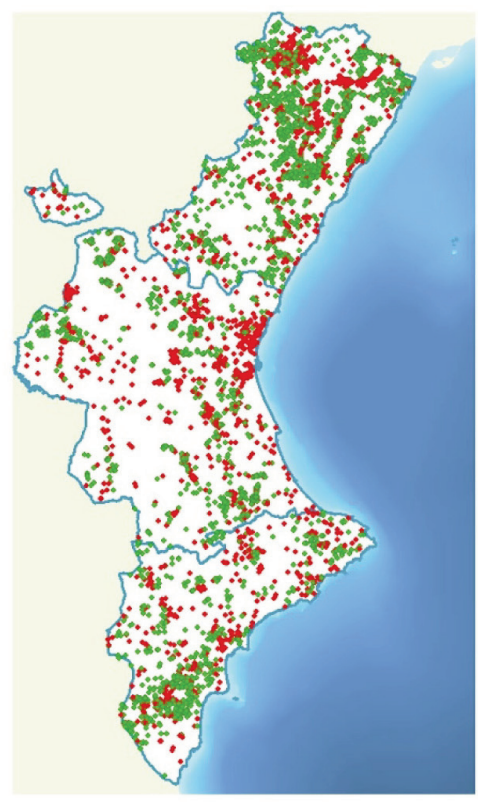

- Explotación en calificación no adecuada

- Explotación en localización adecuada

Figura 6. Mapa de la planificación urbanística de la Comunidad Valenciana (a) y mapa de identificación de las explotaciones en calificaciones urbanísticas adecuadas e inadecuadas (b).

Figure 6. Map of the urban planning of the Valencian Community (a) and identification map of the farms in proper and no-proper urban qualifications (b).

principales donde se concentran explotaciones que incumplen la mayor parte de los factores estudiados, y se pueden analizar, en cada una de estas zonas, los principales riesgos que presentan. La zona más sensible se caracteriza porque el $38 \%$ de las explotaciones incumplen todos los factores, un $19 \%$ no respetan las distancias a núcleos urbanos y entre explotaciones, y que todas incumplen la distancia mínima entre explotaciones de distinta especie. En la siguiente zona más sensible, el $33 \%$ de las explotaciones incumplen las distancias mínimas que deben guardar con respecto a los núcleos urbanos y 
a)

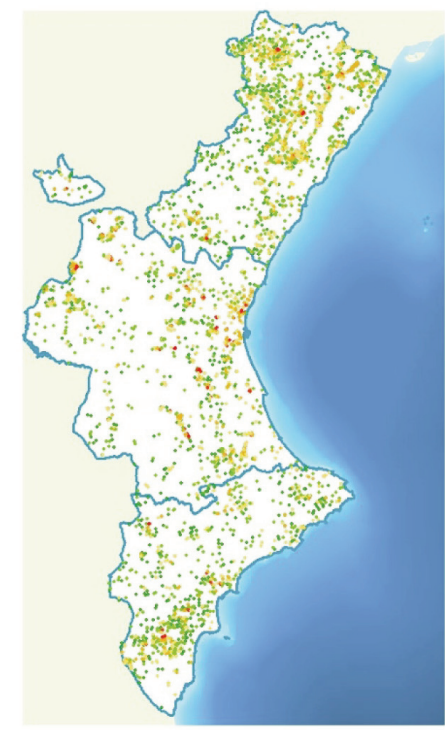

\begin{tabular}{|l|}
\hline Índice de riesgo \\
- Nulo \\
- Muy bajo \\
Bajo \\
- Alto \\
- Muy alto \\
\hline
\end{tabular}

b)

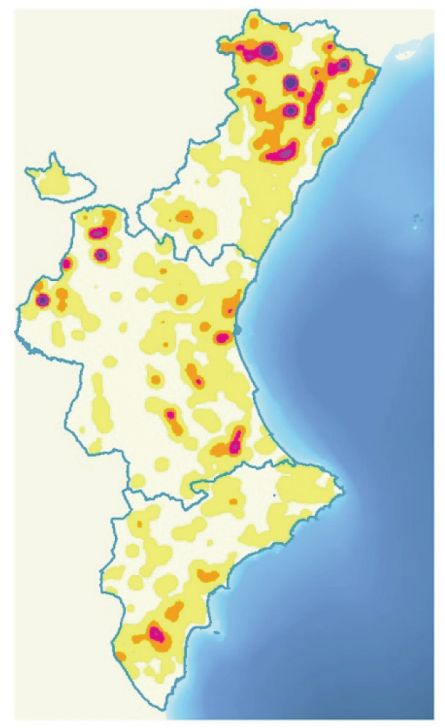

\begin{tabular}{|l|}
\hline Áreas sensibles \\
$\square$ Nulo \\
$\square$ Muy bajo \\
Bajo \\
$\square$ Medio \\
Alto \\
$\square$ Muy alto
\end{tabular}

Figura 7. Mapas de riesgo de las explotaciones (a) y áreas sensibles respecto a los criterios (b). Figure 7. Maps of risk for farms (a) and sensitive areas with respect to criteria (b).

otras explotaciones, un $34 \%$ incumplen las distancias mínimas entre explotaciones tanto de la misma especie como de cualquier otra, y además, todas incumplen la distancia mínima entre explotaciones de distinta especie.

\section{Discusión}

La importancia de la planificación del sector ganadero es el paso previo a la correcta definición de las políticas sectoriales y medioambientales para la regulación del sector, especialmente en áreas con fuertes conflictos por el uso del suelo. La realización de predicciones ante distintos escenarios de las políticas (Louwagie et al., 2012, Kros et al., 2015) puede llevar a conclusiones erróneas si no se conocen con exactitud los riesgos a los que se enfrenta el sector, provocados por la incorrecta ubicación de las explotaciones y originado por la inexistencia de planificación territorial de la ganadería.

En la literatura se encuentran distintas metodologías sobre la planificación territorial de la ganadería basada en la distribución de las explotaciones. Una de las más utilizadas es 
a)

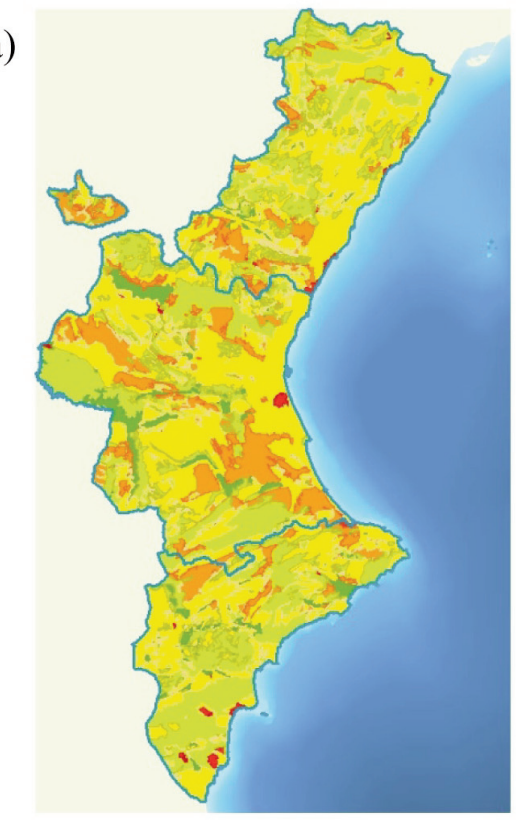

$$
\begin{aligned}
& \text { Vulnerabilidad } \\
& \text { de acuiferos } \\
& \text { - Nulo } \\
& \text { - Muy bajo } \\
& \text { - Bajo } \\
& \text { - Medio } \\
& \text { - Alto } \\
& \text { - Muy alto }
\end{aligned}
$$

b)

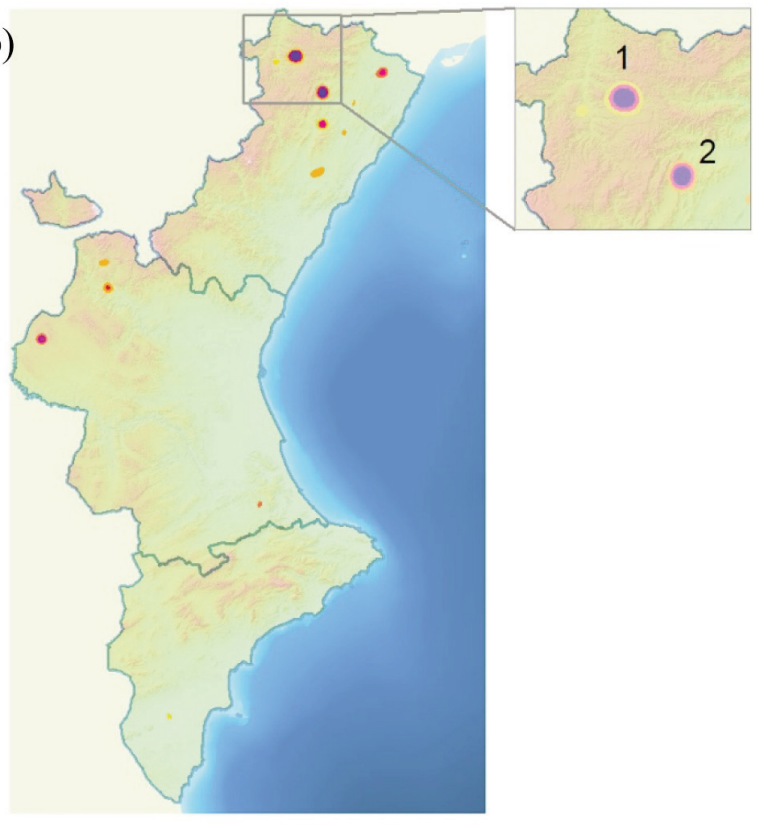

Áreas sensibles/
Vulnerabilidad de acuíferos
-Muy alto, Bajo
-Alto, Alto
-Alto, Medio
-Alto, Bajo
-Alto, Muy bajo
-Medio, Alto
-Medio, Medio
-Medio, Bajo

Figura 8. Mapa de vulnerabilidad de acuíferos en la Comunidad Valenciana (a) y mapa de identificación de áreas sensibles según la vulnerabilidad de los acuíferos (b).

Figure 8. Map of vulnerability for aquifers in the Valencian Community (a) and identification map for sensitive areas according to the aquifers vulnerability (b).

el enfoque estadístico empírico (Mertens et al., 2002; Aspinall, 2004; Neumann et al., 2009; Verburg y Overmars, 2009), en el que se utilizan las probabilidades específicas para la distribución del ganado según el uso del suelo agrario con el fin de determinar las fuerzas motrices espaciales de la dinámica de uso del suelo. Este enfoque es muy intensivo de datos y sólo podía aplicarse en áreas geográficas que tuvieran información suficiente, quedando en caso contrario, un gran número de espacios territoriales donde no puede ser aplicado. Adicionalmente, y sobre esta base de información utilizada en el en- 
foque estadístico empírico, se aplican normas de idoneidad basadas en la opinión de expertos o relaciones estadísticas con el fin de jerarquizar las relaciones del ganado con el uso del suelo (Neumann et al., 2009). Estas relaciones basadas en la opinión de expertos solo se pueden aplicar en el caso de explotaciones ganaderas extensivas, debido a que utilizan mucho suelo agrario, y no en explotaciones intensivas que prácticamente no utilizan suelo agrario. En estos estudios no pueden reducir la escala a la propia explotación en la determinación de riesgos asociados.

En este estudio se propone una metodología, en la que utilizando la información cartográfica del área de estudio y georreferenciando la posición de las explotaciones, se puede reducir la escala hasta la explotación y determinar con exactitud los riesgos sectoriales y medioambientales asociados a cada una de ellas, tanto para explotaciones ganaderas extensivas como para las intensivas, y de esta forma, poder localizar las zonas más problemáticas.

Los riesgos sectoriales han sido ampliamente estudiados, especialmente el riesgo de transmisión de enfermedades entre especies y el riesgo para la salud pública (Van Boeckel et al., 2012Lupindu et al., 2015; Richter et al., 2015). En cambio, en estos estudios solo se analizan las distancias entre explotaciones y núcleos urbanos.

La calificación urbanística en la que se encuentran las explotaciones ganaderas es tenida en cuenta a la hora de ubicar una nueva instalación, pero los planes urbanísticos han ido cambiando, y actualmente, se pueden encontrar granjas en calificaciones que no son idóneas, todo esto, unido a la expansión de la ganadería intensiva puede ser un riesgo de contaminación de espacios o reservas naturales(Kros et al., 2015). En la mayoría de los estudios de planificación de la ganadería no se tiene en cuenta esta variable.

\section{Conclusiones}

La presión social hacia el cumplimiento de las nuevas exigencias legislativas ha provocado que el sector ganadero esté inmerso en una profunda modificación estructural. Esta reestructuración del sector no afecta del mismo modo en todas las regiones y a todas las especies ganaderas, siendo más sensibles las zonas rurales con ganadería intensiva.

La CV es una región con elevados conflictos por el uso del suelo, especialmente en las zonas costeras, en donde la actividad agraria y ganadera se ha trasladado a zonas intermedias y de interior.

En este estudio se han evaluado espacialmente los riesgos de todas las explotaciones ganaderas en actividad de la CV, según las normativas vigentes, tanto las referentes al cumplimiento de las normas de seguridad sanitarias del sector como sobre la salud pública (distancias sanitarias entre explotaciones y núcleos de población) y el medioambiente, debido a la ubicación de las explotaciones en calificaciones del suelo no apropiadas, ya que pueden ser más sensibles a ser contaminadas

Esta metodología permite determinar los riesgos de cada explotación ganadera y, además, localizar las áreas con mayor número de explotaciones ganaderas problemáticas y, por tanto, áreas muy sensibles.

Además, es una metodología transportable a cualquier área geográfica y permite obtener una imagen precisa de los riesgos actuales en el sector ganadero $y$, por tanto, ser el punto de partida para que la definición de los instrumentos de política en este sector se adecúe a las dificultades de cada área problemática.

En la CV se han detectado principalmente dos áreas sensibles. En el área más problemática el $40 \%$ de las explotaciones están incumpliendo las normas vigentes, ninguna de las explotaciones respeta la distancia a otras 
explotaciones $y$, además, la mitad de estas no cumplen la distancia a los núcleos urbanos. En la otra área problemática, el $33 \%$ de las explotaciones incumple las distancias mínimas a los núcleos urbanos y otras explotaciones. Además, se ha comprobado que la ubicación de las explotaciones es preferentemente en los usos del suelo adecuados, no encontrando riesgos potenciales de contaminación en áreas protegidas.

Se ha conseguido detectar las áreas problemáticas en una zona de ganadería intensiva y con elevados conflictos por el uso del suelo, facilitando que la adopción de medidas políticas se pueda adecuar a la problemática del sector en la CV, permitiendo una mejora sobre el propio sector, sobre el medio ambiente y la salud pública, con el fin de acercar más el concepto de multifuncionalidad de las áreas agrarias más conflictivas.

\section{Referencias bibliográficas}

Amador J, Dominguez J (2005). Application of geographical information systems to rural electrification with renewable energy sources. Renewable Energy 30: 1897-1912. https://doi.org/ 10.1016/j.renene.2004.12.007

Aspinall R (2004). Modelling land use change with generalized linear models - A multi-model analysis of change between 1860 and 2000 in Gallatin Valley, Montana. Journal of Environmental Management 72(1-2): 91-103. https://doi. org/10.1016/j.jenvman.2004.02.009

Baban SMJ, Parry T (2001). Developing and applying a GIS-assisted approach to locating wind farms in the UK. Renewable Energy 24: 59-71. https://doi.org/10.1016/S0960-1481(00)00169-5

Bartelt-Hunt S, Snow DD, Damon-Powell T, Miesbach D (2011). Occurrence of steroid hormones and antibiotics in shallow groundwater impacted by livestock waste control facilities. Journal of Contaminant Hydrology 123(3-4): 94-103. https://doi.org/10.1016/J.JCONHYD.2010.12.010
Basnet B, Apan A, Raine S (2002). Geographic information system based manure application plan. Journal of Environmental Management 64(2): 99-113. https://doi.org/10.1006/jema. 2001.0484

Batzias FA, Sidiras DK, Spyrou EK (2005). Evaluating livestock manures for biogas production: a GIS based method. Renewable Energy 30(8): 1161-1176. https://doi.org/10.1016/J.RENENE. 2004.10.001

Boender GJ, Van Den Hengel R, Van Roermund HJW, Hagenaars TJ (2014). The influence of between-farm distance and farm size on the spread of classical swine fever during the 1997-1998 epidemic in the Netherlands. PLOS ONE 9(4): e95278 https://doi.org/10.1371/journal.pone.0095278

Brady M, Sahrbacher C, Kellermann K, Happe K (2012). An agent-based approach to modeling impacts of agricultural policy on land use, biodiversity and ecosystem services. Landscape Ecology 27(9): 1363-1381. https://doi.org/10. 1007/s10980-012-9787-3

Calafat C, Gallego A, Quintanilla I (2015). Integrated geo-referenced data and statistical analysis for dividing livestock farms into geographical zones in the Valencian Community (Spain). Computers and Electronics in Agriculture 114: 58-67. https://doi.org/10.1016/j.compag.2015.03.005

Cejudo García E, Maroto Martos JC (2010). La reforma de la PAC 2003: Desacoplamiento, condicionalidad, modulación, desarrollo rural. Scripta Nova. Revista Electrónica de Geografía y Ciencias Sociales XIV(318): 1-14. Consultado en: https://www.researchgate.net/profile/Eugenio_Cejudo/publication/43692857_La_reforma_de_la_PAC_2003_desacoplamiento_condicionalidad_modulacion_desarrollo_rural/links 1564d999d08ae1ef9296ab766.pdf

Centner TJ (2004). New regulations to minimize water impairment from animals rely on management practices. Environment International 30(4): 539-545. https://doi.org/10.1016/J.ENVINT.2003.10.010

de Vos A, Cumming GS, Cumming DHM, Ament JM, Baum J, Clements HS, Grewar jD, Macie- 
jewski K, Moore C (2016). Pathogens, disease, and the social-ecological resilience of protected areas. Ecology and Society 21(1): 20. https://doi. org/10.5751/ES-07984-210120

Deunert F, Lennartz B, Tiemeyer B (2007). Legislative effects on the development of surface water quality in rural areas in Northern Germany. Journal of Cleaner Production 15(16): 1507-1513. https://doi.org/10.1016/J.JCLEPRO.2006.07.035

Djodjic F, Montas H, Shirmohammadi A, Bergström L, Ulén B (2002). A Decision Support System for Phosphorus Management at a Watershed Scale. Journal of Environmental Quality 31: 937-945. https://doi.org/10.2134/jeq2002.9370

Friedrich, T, Kassam A (2016). Food security as a function of Sustainable Intensification of Crop Production. AIMS Agriculture and Food 1(2): 227238. https://doi.org/10.3934/agrfood.2016.2.227

Herviu B (1996). Agricultura y territorio: nuevas orientaciones para la política agraria. Revista española de economía agraria 176: 167-192.

Jarvis SC, Ledgard S (2002). Ammonia emissions from intensive dairying: A comparison of contrasting systems in the United Kingdom and New Zealand. Agriculture, Ecosystems and Environment 92(1): 83-92. https://doi.org/10.1016/ S0167-8809(01)00283-3

Joost S, Colli L, Baret PV, Garcia JF, Boettcher PJ, Tixier-Boichard M, Ajmone-Marsan P (2010). Integrating geo-referenced multiscale and multidisciplinary data for the management of biodiversity in livestock genetic resources. Animal Genetics 41(SUPPL. 1): 47-63. https://doi.org/ 10.1111/j.1365-2052.2010.02037.x

Kros J, Bakker MM, Reidsma P, Kanellopoulos A, Jamal Alam S, de Vries W (2015). Impacts of agricultural changes in response to climate and socioeconomic change on nitrogen deposition in nature reserves. Landscape Ecology 30(5): 871885. https://doi.org/10.1007/s10980-014-0131-y

Louwagie G, Northey G, Finn JA, Purvis G (2012). Development of indicators for assessment of the environmental impact of livestock farming in Ireland using the Agri-environmental Footprint Index. Ecological Indicators 18: 149-162. https://doi.org/10.1016/j.ecolind.2011.11.003
Lupindu AM, Dalsgaard A, Msoffe PLM, Ngowi HA, Mtambo MM, Olsen JE (2015). Transmission of antibiotic-resistant Escherichia coli between cattle, humans and the environment in peri-urban livestock keeping communities in Morogoro, Tanzania. Preventive Veterinary Medicine 118(4): 477-482. https://doi.org/10.1016/j.prevetmed. 2014.12.005

Mahin TD (2001). Comparison of different approaches used to regulate odours around the world. Water Science and Technology 44(9): 87-102.

Mertens B, Poccard-Chapuis R, Piketty MG, Lacques $A E$, Venturieri $A$ (2002). Crossing spatial analyses and livestock economics to understand deforestation processes in the Brazilian Amazon: The case of São Félix do Xingú in South Pará. Agricultural Economics 27(3): 269294. https://doi.org/10.1111/j.1574-0862.2002. tb00121.x

Molina-Ruiz J, Martínez-Sánchez MJ, Pérez-Sirvent $\mathrm{C}$, Tudela-Serrano ML, García Lorenzo ML (2011). Developing and applying a GIS-assisted approach to evaluate visual impact in wind farms. Renewable Energy 36(3): 1125-1132. https://doi.org/10.1016/j.renene.2010.08.041

Neumann K, Elbersen BS, Verburg PH, Staritsky I, Pérez-Soba M, de Vries W, Rienks WA (2009). Modelling the spatial distribution of livestock in Europe. Landscape Ecology 24(9): 1207-1222. https://doi.org/10.1007/s10980-009-9357-5

Nolan BT, Ruddy BC, Hitt KJ, Helsel DR (1997). Risk of nitrate in groundwaters of the United States - A national perspective. Environmental Science and Technology 31(8): 2229-2236. https://doi.org/10.1021/es960818d

Palomo I, Martín-López B, Potschin M, HainesYoung R, Montes C (2013). National Parks, buffer zones and surrounding lands: Mapping ecosystem service flows. Ecosystem Services 4: 104-116. https://doi.org/10.1016/j.ecoser.2012. 09.001

Perez Espejo R (2006). Costs of the Wastewater Standard in Pig Production in Mexico. Environment, Development and Sustainability 8(3): 391411. https://doi.org/10.1007/s10668-005-8349-0 
Pérez Yruela M, Sumpsi JM, Lopez Iglesias E, Bardaji I (2016). El enfoque territorial del desarrollo en zonas rurales : de la teoría a la práctica. En Desarrollo en territorios rurales. Estudios comparados en Brasil y España (Ed. Campinas AE) pp. 25-74.

Pettit CJ (2005). Use of a Collaborative GIS-Based Planning-Support System to Assist in Formulating a Sustainable-Development Scenario for Hervey Bay, Australia. Environment and Planning B: Urban Analytics and City Science 32(4): 523-545. https://doi.org/10.1068/b31109

Plaza Gutiérrez JI (2006). Territorio, Geografía Rural Y Políticas Públicas. Desarrollo Y Sustentabilidad En Las Áreas Rurales. Boletín de la A.G.E. 41: 69-95.

Recatalá L, Ive JR, Baird IA, Hamilton N, Sánchez $J$ (2000). Land-use planning in the Valencian Mediterranean Region: Using LUPIS to generate issue relevant plans. Journal of Environmental Management 59(3): 169-184. https://doi.org/ 10.1006/jema.2000.0350

Richter CH, Custer B, Steele JA, Wilcox BA, Xu J (2015). Intensified food production and correlated risks to human health in the Greater Mekong Subregion: A systematic review. Environmental Health : A global access science source 14(1): 1-13. https://doi.org/10.1186/s12940-015-0033-8

Ruiz-Urrestarazu E, Galdós-Urrutia R (2013). Actividad Agraria Y Paisaje. La Ganadería, Clave En La Conservación Del Paisaje Vasco-Atlántico. Boletín de la Asociación de Geógrafos Españoles 63: 379-398. Consultado en: http://www.age-geografia.es/ojs/index.php/bage/article/viewFile/1619/1539

Salvà Catarineu M, Panareda Clopés JM, Nuet Badía J (2004). El análisis a gran escala y las nuevas tecnologías: una nueva interpretación geográfica del espacio para la gestión territorial. Scripta nova. Revista electrónica de geografía y ciencias sociales, VIII(170). Consultado en: http://www.ub.edu/geocrit/sn/sn-170-16.htm

Schauberger G, Lim TT, Ni JQ, Bundy DS, Haymore BL, Diehl CA, Duggirala RK, Heber AJ (2013). Empirical model of odor emission from deeppit swine finishing barns to derive a standardized odor emission factor. Atmospheric Environment 66: 84-90. https://doi.org/10.1016/j. atmosenv.2012.05.046

Segrelles Serrano J (2012). La Política Agraría Común de la Unión Europea y la soberanía alimentaria de América Latina: una interrelación dialéctica. Scripta Nova. Revista Electrónica de Geografía y Ciencias Sociales XVI(415). Consultado en: http://www.ub.edu/geocrit/sn/sn-415.htm

Sumpsi Viñas JM (1996). La agricultura española ante los nuevos escenarios de la PAC. Revista Española de Economía Agraria 176-177: 265-304. Consultado en: http://www.mapama.gob.es/ministerio/ pags/biblioteca/revistas/pdf_reea/r176_10.pdf

Tzanopoulos J, Jones PJ, Mortimer SR (2012). The implications of the 2003 Common Agricultural Policy reforms for land-use and landscape quality in England. Landscape and Urban Planning 108(1): 39-48. https://doi.org/10.1016/j.landur bplan.2012.07.012

Van Boeckel TP, Thanapongtharm W, Robinson T, D'Aietti L, Gilbert M (2012). Predicting the distribution of intensive poultry farming in Thailand. Agriculture, Ecosystems and Environment 149: 144-153. https://doi.org/10.1016/j.agee. 2011.12.019

Verburg PH, Overmars KP (2009). Combining topdown and bottom-up dynamics in land use modeling: Exploring the future of abandoned farmlands in Europe with the Dyna-CLUE model. Landscape Ecology 24(9): 1167-1181. https://doi. org/10.1007/s10980-009-9355-7

(Aceptado para publicación el 12 de julio de 2018) 